\title{
Making Sense of Wisdom Management
}

\author{
Peeter Müürsepp ${ }^{1, *}$ \\ ${ }^{1}$ Department of Law, Tallinn University of Technology Tallinn, Estonia \\ ${ }^{1}$ peeter.muursepp@ttu.ee* \\ * corresponding author
}

(Received June 2, 2021 Revised June 12, 2021 Accepted June 18, 2021, Available online July 1, 2021)

\begin{abstract}
An effective manager has to be wise. The paper analyzes different approaches to wisdom and makes proposals about how to apply them for making sense of wisdom management. The focus of the paper, however, is the relationship between wise management and wise leadership. At the basis of a definite understanding of knowledge management, we give the main reasons why wisdom is crucial for effective leadership, especially in self-organizing organizations. Practice is crucial but the basic human faculties of morality and creativity have to be accounted for as well.
\end{abstract}

Keywords: knowledge-management; leadership; practice; self-organization; wisdom; wisdom economy; wisdom management;

\section{Introduction}

Several years ago, economists and management people learned about the term 'policy economy'. The rhetoric of the approach's founders was ambitious. Their inventions should have dethroned the knowledge economy of today. However, after the initial excitement, nothing special followed. Hardly anyone except the early contributors paid attention to the new developments. Wisdom economics has earned its place as a philosophy, as a style of economic thought but nothing more. The focus is still on knowledge - knowledge economy, knowledge transfer, etc.

This is all true as far as the general discipline of economics is concerned. It is interesting, however, that the situation is at least somewhat different regarding management. The concept of wisdom management seems to be gaining momentum. So far, we can only hypothesize about the reasons for this difference. It may be that the term 'wisdom' has more to do with humans than with a broad abstract field. Management, in contrast to economics, is an activity that is directly driven by human actors. After all, management doesn't even need to be associated with economics or business. This is possible and should happen in all walks of life, both near and far. We will take a deeper look at the essence of the concept of wisdom management, but first, let's define what we will mean by wisdom. Obviously, an abstract philosophical understanding of the term in the style of Heraclitus or Heidegger will not work for us. Aristotle's Phronesis does a slightly better job of explaining in our context but having a timestamp, very different from ours, is still very significant. The same is true of Oriental wisdom, be it Confucian, Daoist, Buddhist or otherwise. This philosophical approach helps to take a broad generalist view of mundane issues. However, there is no direct help on practical matters. This is precisely what we seek, namely a truly instrumental understanding of wisdom. However, Oriental wisdom can help us understand the behavior of self-regulating systems, including companies that have been constructed in such a way that they are open to self-regulation. However, this will be a topic for further research.

\section{Literature Review}

Fortunately, there are contemporary approaches to wisdom available that aim for practical purposes. For example, the British philosopher Nicholas Maxwell has been working on this issue for decades and has even expressed his belief that he has discovered what wisdom is. Maxwell explains: "... I must say that I have discovered that science contains, locked in its extraordinary success in gaining knowledge and understanding of the universe, the methodological key 
to wisdom."[1] It is clear that wisdom is not just an emotional thing. according to Maxwell. It's also not a vague feeling. Wisdom, as Maxwell saw it, is purely rational, even instrumental endeavor.

The need for such kind of wisdom, the instrumental one,is explainable in a fully comprehensive discursive manner.There is a long academic tradition in the economic science where the focus has been on knowledge and technological knowhow rather than wisdom. This type of knowledge-inquiry (a term ofNicholas Maxwell)has been successful up to a certain limit, the result being the technologically advanced society we are living in today. Such orientation on knowledge and efficiency production has turned the interest away from real pressing problems of living that humanity is facing, both the so-called global problems and everyday issues us humans are facing in our daily lives. There may be a claim that global problems normally do not connect directly to economic issues. True, but at least the problems of poverty and unequal distribution of wealth still do so. The latter would not necessarily kill anyone and therefore might not qualify as a matter of global concern but the first one can end up as lethal and has done so for a multitude of individuals. Thus, doing research in economics is engaged in the general problem of the limits of knowledge-inquiry. Research in economics and management suffers from the overstressed focus on knowledge pursuit no less than in any other branch of natural or social science.A restart with wisdom (in the instrumental sense) included or even in the focus is necessary. However, what exactly is wisdom in this current instrumental understanding after all.

Nicholas Maxwell has developed a lengthy explanation of what he understands by wisdom: “...the desire, active effort, and capacity to find and achieve what is desired and valuable in life, both for oneself and for others. Wisdom includes knowledge and understanding but goes beyond them also includes: the desire and active struggle for what is valuable, the ability to see what is of value, actually and potentially, in life situations, the ability to experience value, the capacity to use and develop knowledge, technology and understanding needed for value realization. Wisdom, like knowledge, can be understood, not only in personal terms, but also in institutional or social terms. We can thus interpret [the inquiry of wisdom] as a statement: the basic task of rational inquiry is to help us develop wiser ways of life, wiser institutions, social habits and relationships, a wiser world."[2]

It is interesting and important that the central concept of the above explanation is value. More than that, it is very important to acquire the ability to recognize values, to see what is most important for a normal human being to value. This topic, however, can take us away from our main course. We cannot go into too much depth in analyzing the ethical side of this issue. Stillethics remains an integral part of our approach.

We have seen that the focus of academic research must change to include issues concerning the values of life. It involves traditional knowledge issues but more than that. In terms of economics, we can formulate the main tasks as follows. Let's go back to Nicholas Maxwell for help again: "What is the best way to create and distribute wealth?" [3] The problem is far from trivial. There is a normal temptation to seek only wealth maximization. In this way, however, sustainability may be out of sight. After all, this is perhaps the biggest challenge for a liberal market economy. Free market regulations do not involve environmental sustainability. With all the evidence, some rules are unavoidable here. The problem, however, is that it's always problematic to organize something that should be free by definition. This is where the need for wisdom is most evident. Knowledge will not be sufficient to resolve the problematic controversy in setting up a free self-organizing system. We can't know everything. Even the most advanced computers fail here. The human mind has to step in and make the right decisions, i.e. the wise human mind has to act, wisdom has to be implemented.

The question of the fair distribution of wealth is no less complex. Wealth should be distributed fairly, no question about that but how to understand this? Obviously, fair and just don't always mean the same thing. At the same time, large differences in the distribution of wealth usually do not benefit the general welfare of any society. Neither does unification. Again, we need to seek instrumental wisdom to enter.

Of course, there are many other ways to define or explain wisdom other than those proposed by Nicholas Maxwell. Moreover, there is a typology of how to define wisdom available. For example, Shih-Ying Yang, who has studied the understanding of the concept of wisdom among Taiwanese, has proposed the following four groups: 1) a combination 
of personality characteristics or competencies; 2) positive results of human development; 3) a collective system of practical knowledge; 4) processes that arise in the context of real life [4]. Maxwell's definition would probably fall under the first category taking some influence from the fourth as well. Thus, Maxwell's understanding of wisdom is not too far removed from ordinary popular discourse, at least as far as Taiwan is concerned. It is important to note, however, that for the most part, Taiwanese understand wisdom as something practical and close enough to everyday things. Is this attitude something unique in Taiwan? We are not aware of this because there is not enough comparative empirical evidence available. Needless to say, it would be very interesting to run the same survey in many different countries and compare the results.

There is another interesting approach to the concept of wisdom, according to which this state of mind (if we may call it wisdom as such), has six dimensions altogether: 1) practicality as the individual's ability to reason carefully; 2) reflectivity as an individual's ability to remember. on one's past and present life; 3 ) openness as listening and being tolerant of alternative views and possible solutions to problems; 4) have interactional talent as an individual's ability to regulate his own emotions and expressions and understand the emotions and behavior of others; 5) paradoxical as an individual's ability to tolerate uncertainty and ambiguity; 6) ethical sensibility as an individual's ethics and ethical judgments and having experience as an individual's experience with challenging life situations [5]. Again, practicality comes in the first place.

It may not make sense to compare the latter approach to Maxwell's. This approach is different. However, one might still claim that these two approaches involve the same problem which has just been exposed in different ways. One thing is clear though. Maxwell's claim that he has devised a conclusive definition of wisdom is not sufficiently valid. Much remains to be done to understand wisdom, even from the most practical point of view. Perhaps the best outcome in defining wisdom can be a kind of family resemblance from a different sequence of approaches. It is clear, however, that most thinkers who have tried to grasp the essence of wisdom, approach phenomena from the point of view of practical application to mundane matters. This understanding of wisdom has become very common to contemporary thinkers. This is a well-justified emphasis. However, there is a danger here. We must not get caught up in the charm of the direct effects of physical (material) exercise and forget the ethical and emotional side of human existence. Fortunately, more than one 'scholar of wisdom' noticed this.

Now we need to find clues on how to start the successful application of wisdom in management. This cannot be a direct step as can be deduced from the above analysis. First, let's remember what we mean by the term. Next, we will add new insights. However, we must start by understanding the term 'wisdom management'.

\section{Method}

As noted above, over the past few decades, some attention has been paid to the concept of the wisdom economy, which distinguishes it from the knowledge economy. For example, this author has provided an analytical overview of the topic [6]. Somewhat recently, interesting approaches to the chain of knowledge and wisdom have been provided. Regarding a certain approach, the story starts with data and information. Therefore, we got the concept of Data, Information, Knowledge and Wisdom Chain (DIKW). This is the approach of Hey [7]. The concept can be used as a synonym for the Knowledge Pyramid linked to the Information Hierarchy. This type of hierarchical or pyramidal approach refers to different steps of development. Data and information are the basis. This allows us to acquire knowledge. We know the facts. Obviously, we need something more than just knowing the facts. We need the ability to apply knowledge from the information we have. This is precisely what is meant by instrumental wisdom. Understanding the difference between knowledge and wisdom is very important here. We cannot go deep into philosophy with this problem. However, let us remember that in the classical (Platonic) sense knowledge is a kind of belief, the truth of which is justified. Such a concise definition of wisdom does not exist. The case is much more complicated. Wisdom is not belief. The notion of truth and falsehood does not apply to wisdom. The latter is more of a special state of mind that includes all that Nicholas Maxwell has demonstrated (see above) as well as many other things that so far no one has been able to formulate. 
Several authors have made the interesting step of adding intelligence to the hierarchy between knowledge and wisdom. This step will change DIKW to DIKIW [8] (my second stands for 'intelligence'). However, the advantages of DIKIW over DIKW are difficult to understand. Instead, new questions emerge rather than anything being resolved. We get the feeling that intelligence should be something more than knowledge (at least in some ways) but it's not yet wise enough. We can understand this if we limit knowledge to remembering facts but not if we follow the classical definition which describes knowledge as true belief that is justified.

There is an understanding that to understand individual policy management must begin by analyzing the phenomenon of wisdom in organizations. Obviously, there is a close relationship here because there can be no organization without individuals. One might say that there are two sides to the same coin situation here.

Let us remember that we are talking about wisdom management, not just wisdom economics. Management means that people deal with people or rather, one person deals with a group of people. However, organizational wisdom can hardly be understood meaningfully as the sum of the policies of all its employees. Such a formulation already sounds a bit funny. However, sometimes we can find confidence that individual wisdom translates into the wisdom of an organization. Obviously, organizations must learn how to benefit from individuals. How to do this most efficiently is a very important task. It is interesting but perhaps quite justifiable that discretion in the context of management has acquired practical connotations. At the same time, one can see strong references to the need for spirituality. We will not follow these instructions. Let's admit that a certain amount of dedication, courage, and self-respect is required to achieve managerial wisdom in addition to objective criteria.

There is an interesting observation by Arunav Banerjee [9] which states that the proper treatment of policy management requires a specific knowledge management model as a basis. Banerjee started from the DIKW idea that we discussed above. He calls this idea 'the pattern of relationships between disparate data and information'. Banerjee adds his own explanation of what knowledge management is, bringing up the concept of knowledge assets. In this treatment, knowledge management becomes a system that works on the basis of knowledge assets and processes related to knowledge assets. Knowledge assets Banerjee understands as follows: “. .. is knowledge about markets, products, technologies, and organizations, which a business has or needs to have and that enables its business processes to generate profits, add value, etc."'[10]

Banerjee's proposed model includes two rooms, the Template Room or Indoor Room and the Update Room or Outer Room. The purpose of the former is to organize and structure the flow of knowledge. It consists of a series of "knowledge templates". Templates play an important role in the model. According to Banerjee, templates are related to the business processes of an organization and are placed in a hierarchical order of levels.

As the name suggests, the purpose of the Chamber of Updates is to coordinate the process of constant knowledge updating.

The Template Space is structured like a digital library. The Update Rooms are organized by process. This means that the focus is on methodology. "It combines methodologies of gathering information, updating information, choosing between replacements, additions and updates, etc."[11]

Banerjee claims that policy management has not been a separate topic in the academic literature. However, he argues that the concept of wisdom management plays a special role in its application. This is an important concept that allows understanding the interaction between the two rooms of the knowledge management model that he has proposed. There is a need for wisdom in action there, i. e. instrumental wisdom. Banerjee stated: "It (policy management -PM) has to do with the process of updating patterns in the inner space as opposed to information or knowledge in the outer space."[12] Needless to say, the application of such wisdom is quite complex. narrow. However, it points to an area where capacities like wisdom are needed to make things work.

In some other approaches one can find strange, even quite unreasonable, ideas about the links between wisdom and knowledge.For instance, there is a claim that wisdom has to be converted into knowledge before it can be properly managed.The reason for such position is in a more general understanding of knowledge than we normally have in 
management, the philosophical one. If we were to convert wisdom back into knowledge, why strive for wisdom at all.

There is also a belief in a certain kind of circularity claiming that the growth of knowledge produces wisdom and the growth of wisdom on its part helps to produce more knowledge.This is a misunderstanding of the essence of wisdom.It is different from what we normally mean by knowledge. The circularity under question would actually mean that there is no real difference between knowledge and wisdom. This approach could be accepted if we introduce two levels of knowledge and abandon wisdom altogether. However, there seems to be no real reason for such a move.

\section{Results and Discussion}

Let's rephrase the title of this subsection. There are two types of managers: administrators and leaders. There's an important twist here though. Every leader must be a manager but of course not every administrator is a manager. The main job of an administrator-type manager is to keep an organization in order and keep it that way. It's definitely unfair to say that this type of manager doesn't have to be wise. However, accurate knowledge and timeliness may be more important to this type of manager regarding the decisions they make and their actions.

Leaders have to be wise, that's for sure. What does it actually mean? Some people believe that the English word 'commendable' is the best characterization of a wise leader. However, commendable is an assessment that may be given to someone who tries but does not necessarily succeed. However, discretion can be added to anything of course. A commendable person should possess the five traits of wisdom: the capacity for cognitive complexity; the capacity to understand and question a situation; express creativity and logic in non-rational processes, the capacity to think creatively and move relying on instinct in their judgment; have a long-term vision and virtue and must be committed to the long-term prosperity of humanity; the capacity to reach people using words, impacts, and actions that express this[13]. Thus, the essence of wise leadership can be understood as a domain-specific or contextual concept to varying degrees [14].

Now one might ask, why not talk about wisdom leadership rather than wisdom management. It is possible to speak of the wisdom of leaders, just as one can speak of the wisdom of any individual from any field. However, looking at it from a disciplinary point of view, there is an abstract approach. Here we meet the discipline of management. The study of leadership has not become an independent scientific discipline so far. Can it do it someday? Maybe but this is not our topic here. Thus, there is no contradiction between talking about wise leaders and wise management.

However, is it wisdom that is directly related to leadership? There are considerations available, some of which are quite simple but at the same time, no one can claim that they are clearly untrue.

For example, Jordi Alemany proposes the following definition: "Wisdom of leadership is the ability to understand how people, events, and situations affect your position and vice versa, combined with the courage to adopt the right actions to produce the right results." [15] That sounds good, especially bringing up the need to have courage is a new step in the context and certainly good. Without the courage to act, wisdom will remain disguised and, in fact, not even exist. But Alemany also proposes a simple formula: Wisdom $=$ Knowledge + Action. This is definitely the essence of effective leadership and it does just that. However, the formula does not serve as a definition of wisdom just for the same reason why knowledge is not only true. belief. One can try with Wisdom $=$ Knowledge + Useful Action. However, the result will not be better than that of Plato's Theaetetus for knowledge. This is even more complicated because we may know what an opinion or belief is and we know what it means for an opinion to be true. Only a matter of justification remains. However, in the case of Alemany's definition of discretion, we have more uncertainty. We don't even know what knowledge really is, much less on the complex subject of useful or effective action.

However, Jordi Alemany definitely deserves credit for pinpointing the main problem that must be solved in order to start moving towards wisdom - the gap between having an idea (knowing something) and successfully implementing an idea in practice. question though whether Alemany's 'wisdom' differed from Gilbert Ryle's 'know how'. We may 
not need new concepts to understand the addition of action to knowledge. This concept has existed in philosophy since the 1940s.

However, there is still more to which Alemany should be credited. Wisdom must definitely be built up from within as he claims. Still another matter is the list of 20 keys to being a wise leader. We will not comment on every key, although there is much to be discussed and critiqued there. We will concentrate on key groups. There are five of them. They are even and contain four keys each. Let's list the groups first:

1) Be courageous

2) Build mutual trust

3) Avoid destructive internal competition

4) Focus on what truly matters

5) Promote people who understand the value of people [16]

These well-taken points are all really about wisdom and not about knowledge. They are all positive and valuable ethical claims. The problem is, however, that they are rather obvious. Without following these guidelines, leader failure is inevitable, at least in the long run. On the other hand, this list is not exhaustive. There is no important emphasis. This is a question of how to incorporate creativity. It can be considered self-evident that a good (wise) leader must be creative. It's easy to formulate requirements, but how to implement them is a completely different matter? A person can develop his own creativity but only to a certain extent which may not be enough. If we don't know how to learn and also how to teach creativity, then we have to rely on self-organization. However, self-organization does not necessarily appear by itself. It takes some effort to turn the company into a self-regulating system that will enhance the creativity of its members. However, there is no other way to build a company that can take on most creative leaders.

The latter is a very important point to make. It seems that self-regulating organizations, despite their name, need wise and creative leaders. A company in which self-organization does not occur can only be managed but no effective leadership can be applied there. Even a wise and creative leader cannot create miracles in such a system. On the other hand, even a self-regulating system cannot develop in its own right without wise leadership. According to Ilya Prigogine, the originator of the self-organization methodology, there is an openness to the exchange of information which is necessary for an organization to be fully self-governing. As a result of the exchange of information, there is often some kind of instability there that the leader must take care of. Caring doesn't necessarily mean stabilizing here. Sometimes it's the other way around. Some moments of instability provide the option to initiate substantial change in the organization. It takes a wise leader to recognize these key moments and act in the interests of the organization based on his wisdom. This is the reason why a leader can utilize the wisdom of management in a much better way than an administrator can. A wise manager must be a leader.

\section{Conclusion}

Our conclusion is clear. Wisdom, as understood today both in academia and at the level of common sense, is a state of mind that manifests itself only through practical activity. For example, Jordi Alemany puts it in a kind but straight-forward way: "The know-do gap is leadership's inability to turn knowledge into action. In other words, it is the leadership's inability to do what they know needs to be done. Obviously no wisdom!'[17] Given this understanding of wisdom, there is a direct relationship between leadership in self-governing companies and the essence of wisdom management. While there are many details that play an important role here, as we saw above, the main point is that wisdom helps to connect knowledge with action. However, wisdom is not just know-how. The concept contains more and covers the emotional part of human life, including morality and creativity. Robots can never be wise leaders because an important side of human wisdom is always lost when we try to apply artificial intelligence to our goals. Being (or not) wise is clearly a human ability. Perhaps artificial intelligence can possess knowledge and even surpass humans in this category but never be able to acquire wisdom. 


\section{References}

[1] Maxwell, N. 2012. Arguing for Wisdom in the University: An Intellectual Autobiography. Philosophia, 40:663-704.

[2] Maxwell, N. 2014. How Universities Can Help Us Create a Wiser World. SOCIETY.

[3] T. Datta, "Management Thinking From the Wisdom," vol. 2, no. 1, 2001.

[4] C. S. Breathnach, "Knowledge and wisdom," Bmj, vol. 322, no. 7278, p. 98, 2001, doi: 10.1136/bmj.322.7278.98/a.

[5] Yang S. H. 2008, “A Process View of Wisdom”, Journal of Adult Development, Vol. 15, 62-75.

[6] Schmit, D. E., Muldoon, J., \& Pounders, K. 2012, "What is Wisdom? The Development and Validation of a Multidimensional Measure. Journal of Leadership, Accountability and Ethics, 9(2),39-54.

[7] Müürsepp, P. 2013. From Knowledge Economy to Wisdom Economy. Proceedings of the Ninth International Conference on Knowledge-Based Economy \& Global Management, Southern Taiwan University of Science and Technology, 41-49.

[8] Hey, J. 2004. "The data, information, knowledge, wisdom chain: the metaphorical link", Intergovernmental Oceanographic Commission.

[9] Liew, A. "DIKIW: Data, Information, Knowledge, Intelligence, Wisdom and their Interrelationships".

[10] Banerjee, A.Knowledge and Wisdom Management www.delhibusinessreview.org/v_2n2/dbrv2n2p.pdf(accessed Sept. 11, 2017).

[11]I. Nonaka, R. Chia, R. Holt, and V. Peltokorpi, "Wisdom, management and organization," Manag. Learn., vol. 45, no. 4, pp. 365-376, 2014, doi: 10.1177/1350507614542901.

[12] A. K. Ekmekçi, S. B. S. Teraman, and P. Acar, "Wisdom and Management: A Conceptual Study on Wisdom Management," Procedia - Soc. Behav. Sci., vol. 150, pp. 1199-1204, 2014, doi: 10.1016/j.sbspro.2014.09.135.

[13] B. McKenna and D. Rooney, "Book Review: Eric H. Kessler and \& James R. Bailey (eds.) Handbook of Organizational and Managerial Wisdom SAGE Publications: Los Angeles 2007. 1xxiii + 579 pp: ISBN 978-1-4129-1561-8 (cloth)," Organ. Stud., vol. 30, no. 4, pp. 447-449, 2009, doi: $10.1177 / 01708406090300040702$.

[14] Ekmekci, A.K., Teraman, S.B.S., Acar, P. 2014. Wisdom and Management: a Conceptual Study on Wisdom Management. Procedia, Social and Behavioral Sciences, 150, 1199-1204.

[15] McKenna, B., Rooney, D. B. Boal, K. 2009. "Wisdom Principles as a meta-theoretical basis for evaluating leadership", The Leadership Quarterly 20, 177-190.

[16] Alemany, J. $2015.20 \quad$ Keys to Leadership Wisdom. https://www.linkedin.com/.../20-keys-leadership-wisdom-jordi-alemany(accessed Sept. 11, 2017).

[17] A. Intezari and D. J. Pauleen, "Wisdom, management and extreme upredictability: A conceptual model," no. September, 2011.

[18] J. Baiget, "Wisdom management: The last frontier," Proc. Eur. Conf. Knowl. Manag. ECKM, pp. 96-100, 2007. 